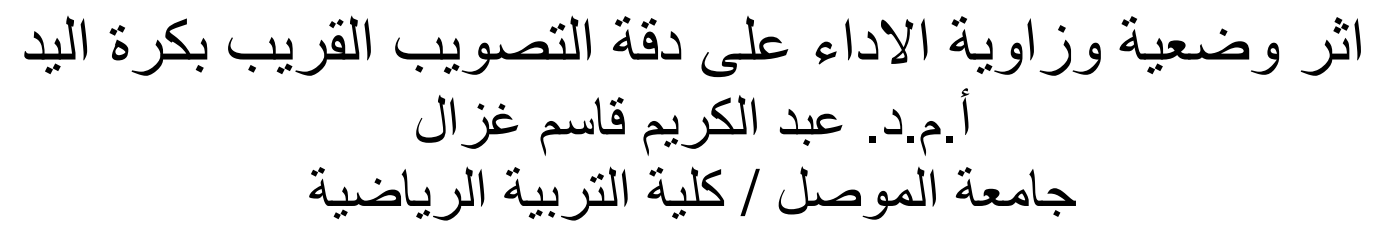

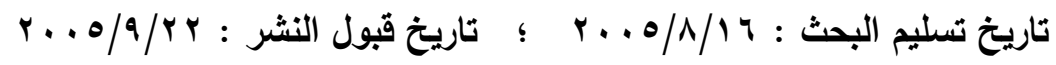

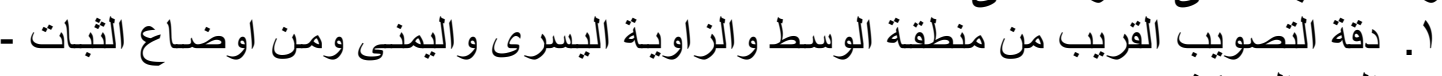

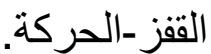

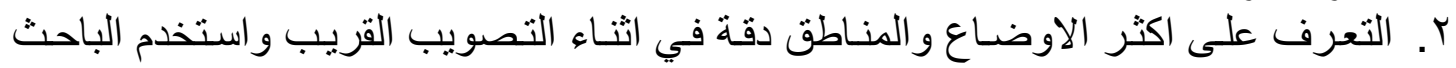

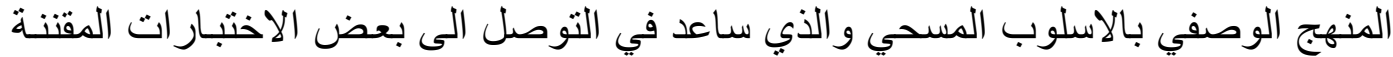

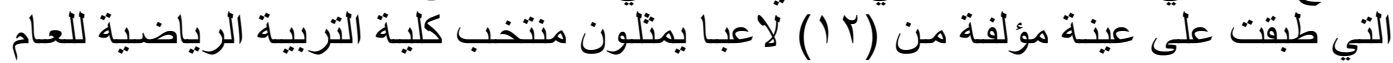

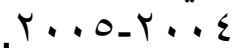

ساعدت هذه الاختبار ات الخاصة بدقة التصويب القريب من اوضاع ومناطق مختلفة الى التوصل الى البيانات الخاصة بالبحث وقد استخدم الباحث تحليل التباين باتجاه و احد للتوصل

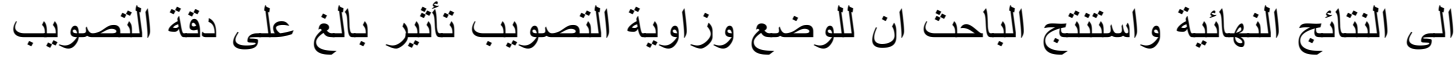
القريب وان اكثر الاوضاع والمناطق دقة كان لصالح وفع الثبات ومن المنطقة المواجهة

\title{
The Effect of Angle and Shooting Position on the Accuracy of Close-Shooting in Team-Handball
}

\section{Dr. Abdul Kareem K. Gazal \\ University of Mosul - College of Sport Education}

\section{Abstract:}

\section{The Research aims at knowing the following:}

- Knowing the accuracy of close-shooting from various area (angle) and different position.

- Knowing which position or area is more accurate than other, when close-shooting in team-handball is used.

The researcher used descriptive method with survey style which helped fulfill some standardized tests which were conducted on group of (12) team-handball's players representing the team of Physical Education College 2004-2005 Those tests were the main tool of collecting data concerning the accuracy of close-shooting. Analysis of variance was used to get the final result.

Then the researcher concluded that each of angle and position of shooting has great effect on the accuracy of close-shooting and the most accurate position was the stationary one from the front area of the goal. 
ان المهارات الاساسية للعبة كرة اليد تمثل واحدة من اهم اوجه التحضير للعب بالنسبة

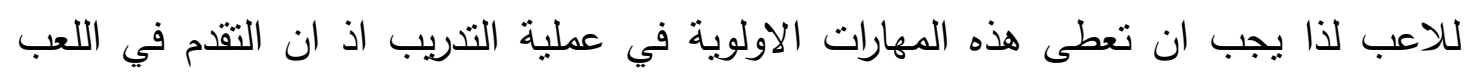

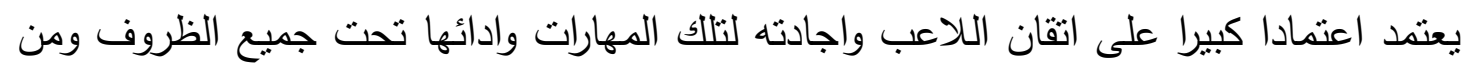

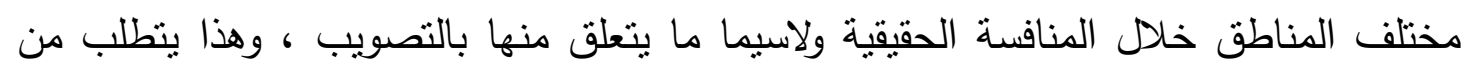

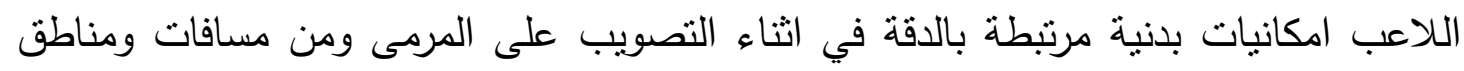

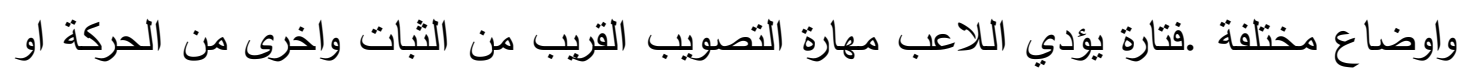

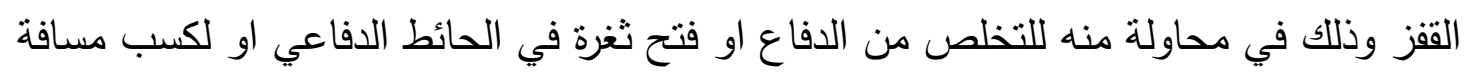
نحو المرمى مما يساعد في زيادة الدقة في اثثاء التصويب ومن ثم زيادة نسبة نجاح هذه لثان المهارة المهمة وبالنظر لارتباط ذلك كله بالناحية البدنية فان هذا يعني ان الدقة والتوافق والرشاقة تكون

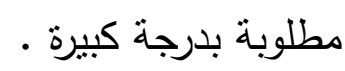

ان فاعلية وتاثير الناحية الهجومية لاي لاعب يعتمد اعتمادا كليا على كفاءته في

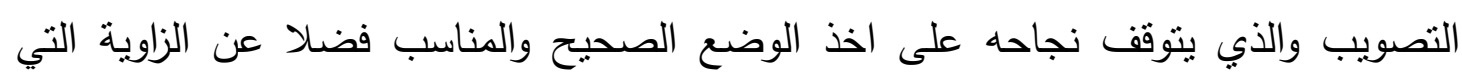

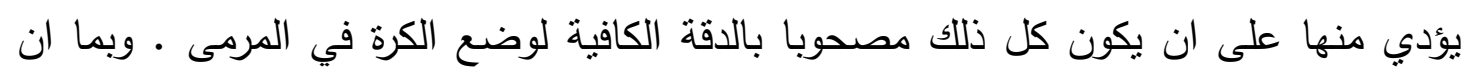

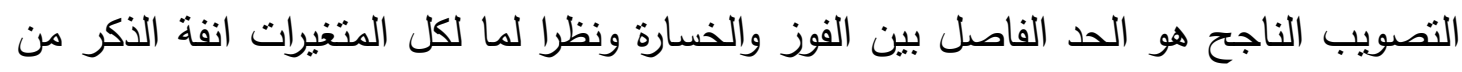
اهمية في نجاح التصويب ولاسيما ما يتعلق منها بتوفر الدقة واختيار الوضع والزاوية المناسبة لهنبة اثثاء تتفيذ التصويب القريب فان اهية البحث تكمن في ضبط هذه المتغيرات ومراعاتها اثثاء

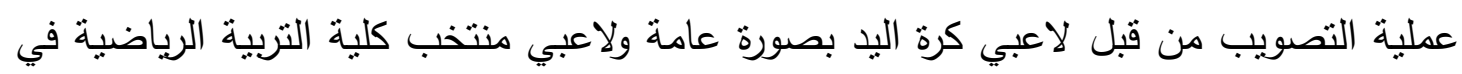

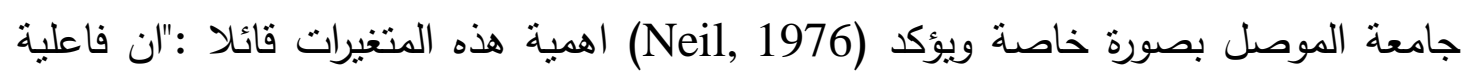
التصويب من جميع الزوايا ومن مختلف المسافات تكمن في دقته فضلا عن سرعة وقوته" (Neil , 1976,43)

كما تكمن اهمية البحث في التعرف على الاوضاع والمناطق او الزوايا الاكثر دقة في

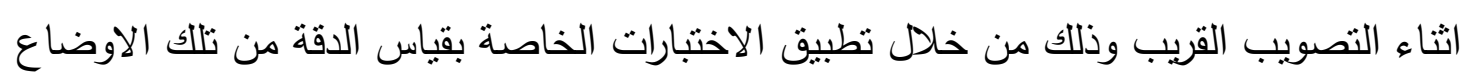

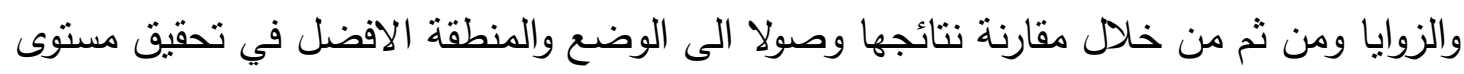

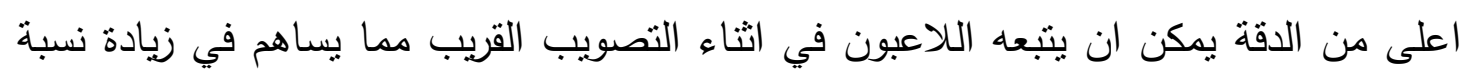


ان التصويب بكرة اليد يمكن ان يصنف على اساس المكان الذي يؤدي منه كان يكون

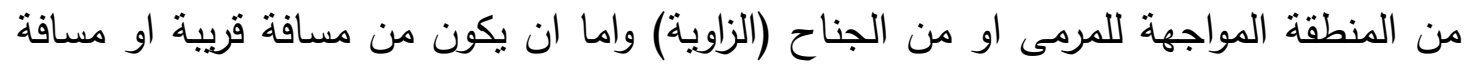
بعيدة ، وكذلك يمكن ان يؤدي كل ذلك من الثبات او القفز او الحركة ، علما بان جميع هذه المتغيرات ترتبط ارتباطا وثثقا بالدقة التي ينفذ بها التصويب وهذه الدقة تعتمد هي الاخرى اعتمادا رئيسيا على مستوى الاداء المهاري للاعب ولاسيما اثتاء تتفيذ التصويب من المناطق

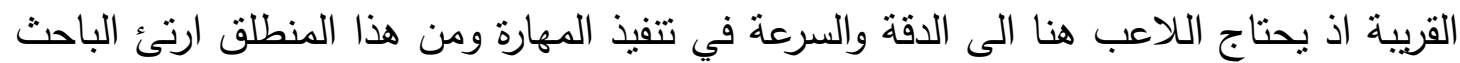
ان يكون محور مشكلة بحثه هو دراسة ددى ثاثير الزاوية او الجهة سواء من الوسط او اليسار

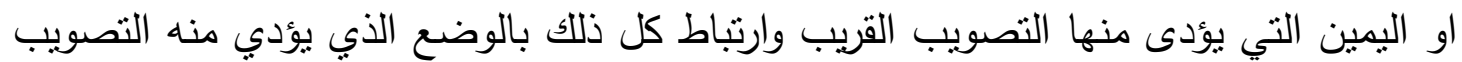

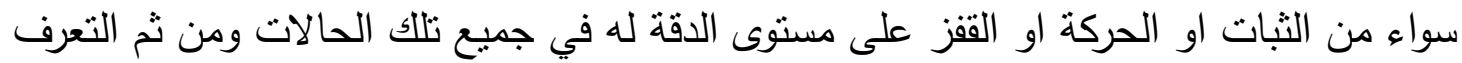
على اكثر المناطق والاوضاع دقة وصولا الى المنطقة والوضع الافضل ويمكن تلخيص مشكلة

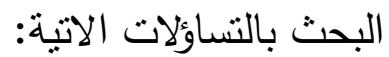

1. هل ان التصويب القريب من المنطقة المواجهة للمرمى اكثر دقة من وضع الثبات او القز

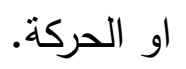

r. هل ان التصويب القريب من الزاوية اليسرى اكثر دقة من وضع الثبات او الققز او الحركة . r. هل ان التصويب القريب من الزاوية اليمنى اكثر دقة من وضع الثنات او الققز او الحركة. ـ. أي من المناطق الثلاثة المنطقة الوسطى او الزاوية اليسرى او الزاوية اليمنى اكثر دقة.

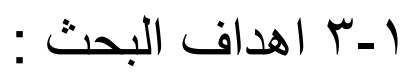

1-r-1 التعرف على دقة التصويب القريب من المنطقة الوسطى (المواجهة) للمرمى ومن الزاوية اليسرى واليمنى ومن اوضاع الثبات ، الققز ، الحركة. 1-r-r التعرف على اكثر مناطق التصويب القريب دقة (الوسط ، الزاوية اليسرى ، الزاوية (اليمنى). 1-r-r التعرف على اكثر الاوضاع(الثبات اوالقفز اوالحركة)دقة في اثناء التصويب القريب. 
1-؟-1 وجود فروق ذات دلالة معنوية بين دقة التصويب القريب من المنطقة المواجهة للمرمى والتصويب من الزاوية اليسرى واليمنى ولصالح المنطقة المواجهة (الوسطى).

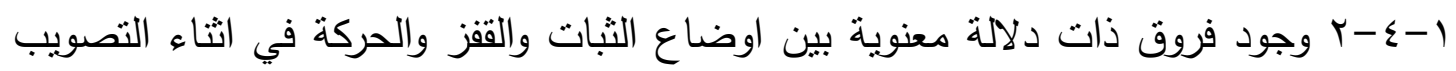

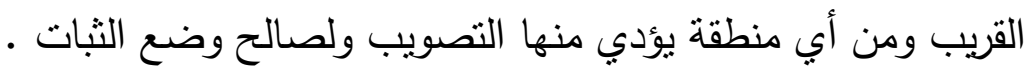

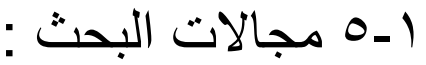

- المجال البشري: لاعبو منتخب كلية التربية الرياضية / جامعة الموصل.

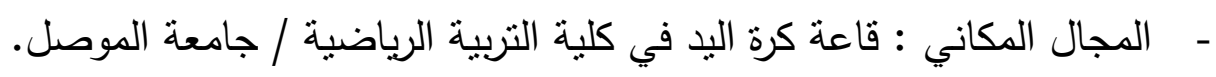

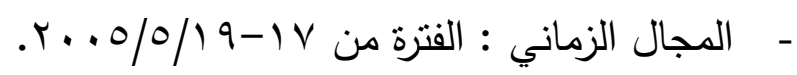

Y - الاطار النظري و البحوث المشابهة : الإن

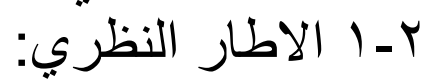

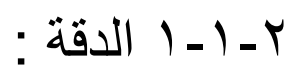

تعد الدقة من العناصر المهمة لنجاح اداء الحركات في العديد من الفعاليات والانشطة

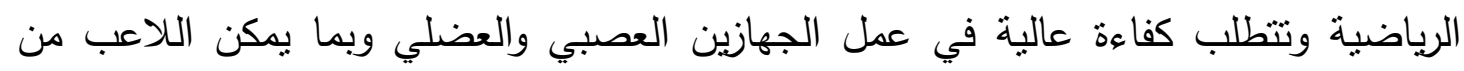

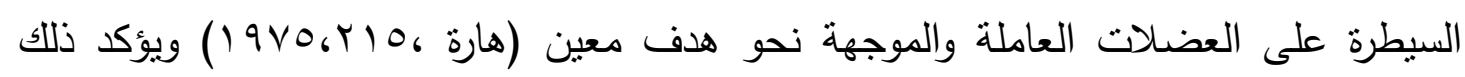
(Larry, 1981) • اذ يشير في تعريفه للاقة "بانها قدرة الفرد على السيطرة على الحركات

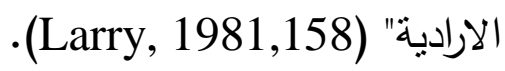

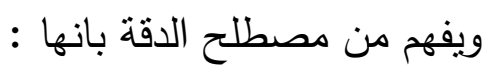
- القدرة على اتقان المهارات الحركية الرياضية .

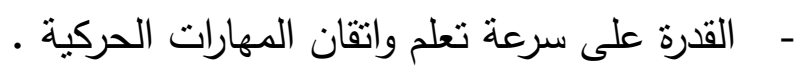

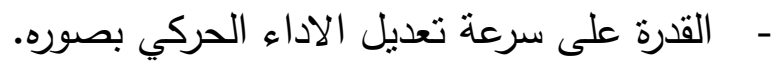

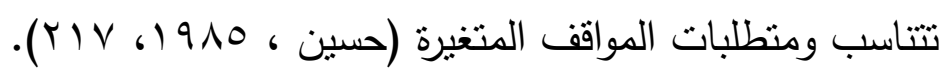

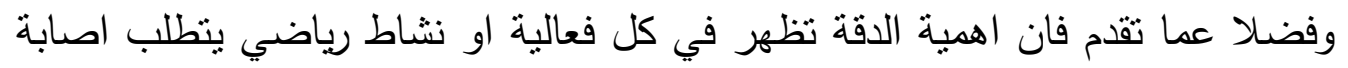
هدف ما ، وعلى الرغم من ذلك فهي صفة خصوصية وتختلف من فعالية الى اخرى ، اذ ان

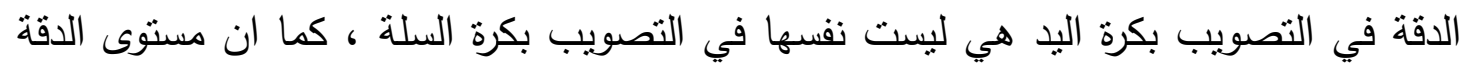

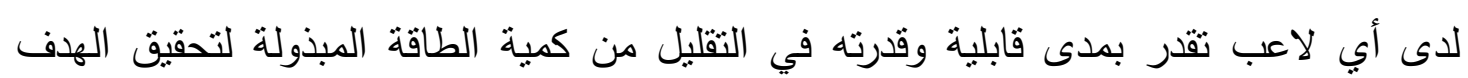

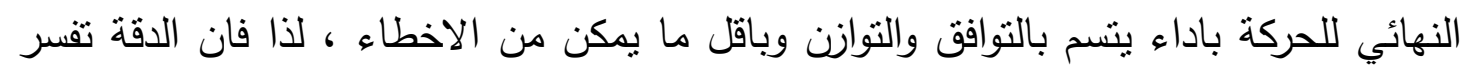

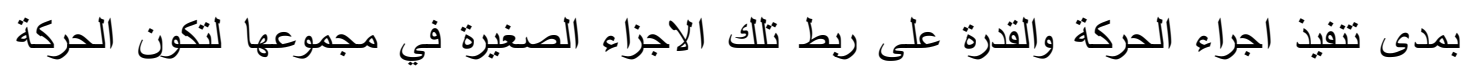


الكاملة وهذا يعني القرة على تقليل الانحرافات او الفارق في الاداء الحركي عن الاداء الامنل

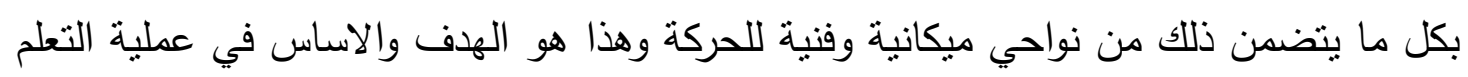

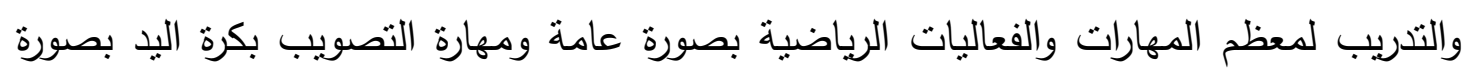

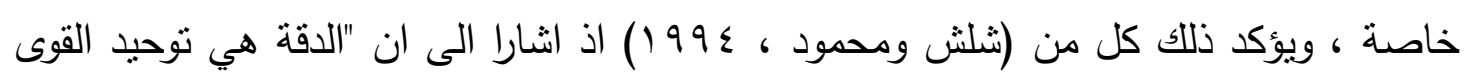

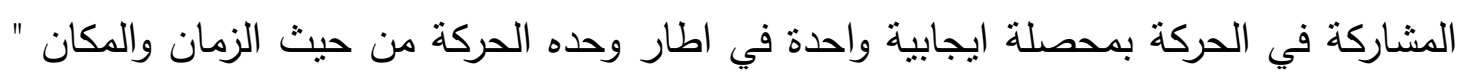

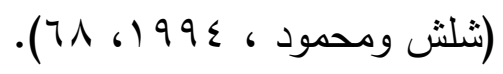

Y - I - Y ب دقة التصويب بكرة البي:

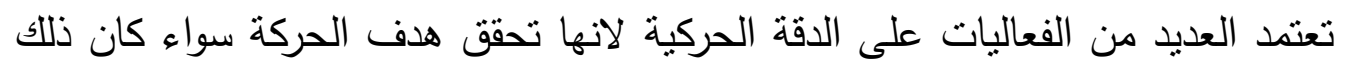
من الحركة او الثبات او القفز وحسب الفعالية او الوضع الذي يكون فيه الفرد الفئ ، ولاسيما اثناء

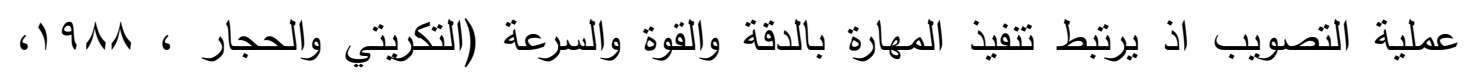

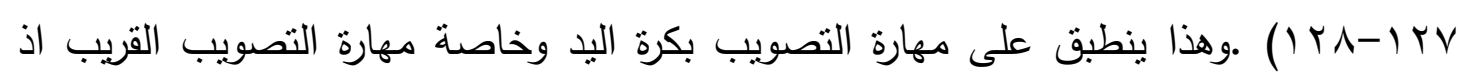

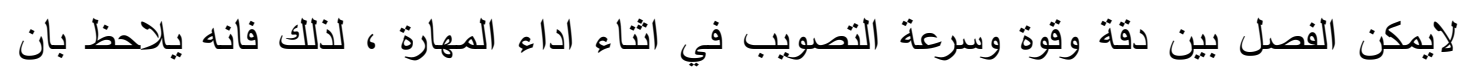
استخدام القوة في التصويب يكون على حساب دقته وهذا ما يظهر واضحا اثناء التصويب البعيد وعلى العكس من ذللك فان هذه العلاقة تكون معكوسة في حالة التصويب القريب اذ ان تركيز

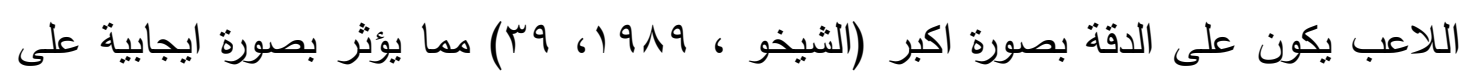
نسبة نجاح مهارة التصويب القريب مقارنة بالتصويب البعيد.

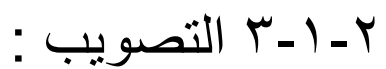
ان مجمل او خلاصة ما يقوم به اللاعبون من مهارات وتطبيق لخطط اللعب فلا بد وان تتنهي باخذ الوضع المناسب للتصويب في محاولة لادخال الكرة بنجاح في المرمى.

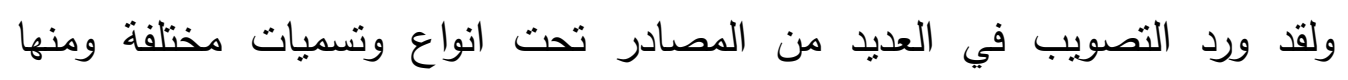
التصويب القريب ، والبعيد والتصويب من السقوط ، وبالوثب او الطيران والقفز ، والتصويب

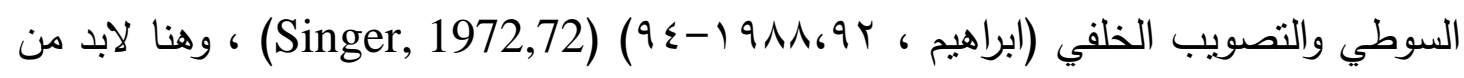

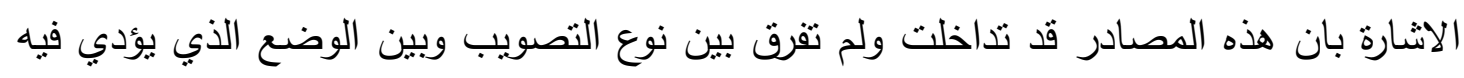

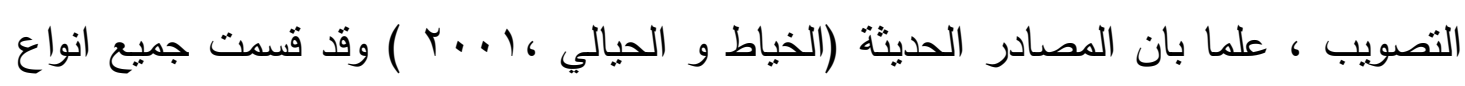

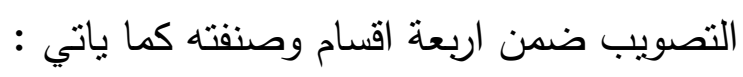
1. التصويب تبعا لمكان المصوب ويدخل ضمن هذا التقسيم : (التصويب البعيد ، التصويب القريب ، التصويب من الزاوية ، التصويب من الوسط ). 
r. التصويب تبعا لحركة المصوب ويشمل : (التصويب من الثبات ، التصويب من الحركة ،

$$
\text { التصويب من القفز ، التصويب من الطيران). }
$$

r. التصويب تبعا لمسار الكرة ويشمل : (التصويب الواطئ ، التصويب العالي ، التصويب لهني

$$
\text { المرتد ، التصويب باسقاط الكرة). }
$$

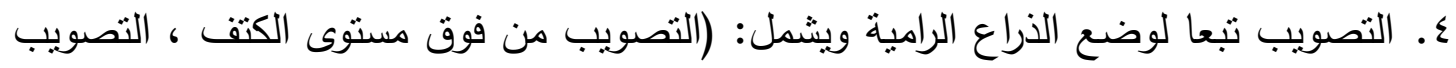

$$
\text { من مستوى الكتف ، التصويب من مستوى الركبة) }
$$

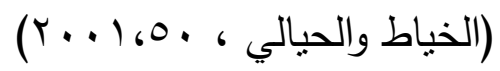

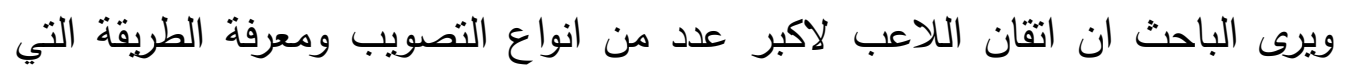

يؤدى بها واختياره التوقيت والزاوية والوضع المناسب للتصويب سوف يساعد كل ذللك في زيادة تاثير وفاعلية اللاعب في تسجيل اكبر عدد من الاهداف.

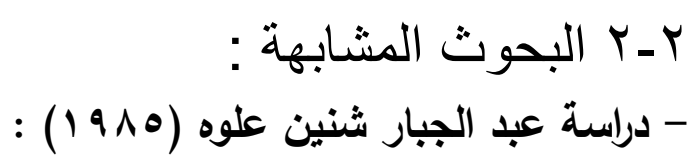

هدفت الدراسة الى التعرف على فاعلية التصويب من منطقة الزاوية والساعد في اصابة الهدف واهمية كل منطقة ، فضلا عن التعرف على اهم انواع التصويب ، وقد نفذت الدراسة

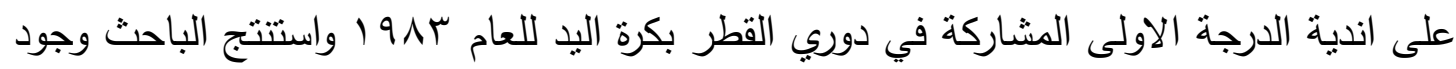

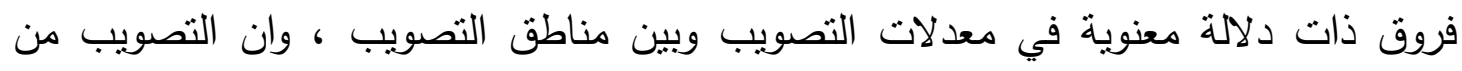
الزاوية او الساعد اكثر نجاحا واقل فثلا من التصويب من المنطقة المواجهة للمرمى (علوه،

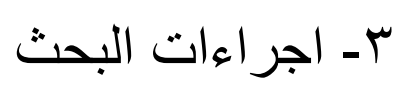

r- ا منهج البحث : استخدم الباحث المنهج الوصفي لملائمته لطبيعة البحث

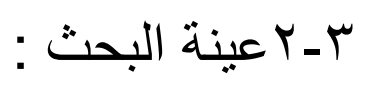

اجرى البحث على لاعبي منتخب كلية التربية الرياضية بكرة اليد ، حيث تم اختيارهم

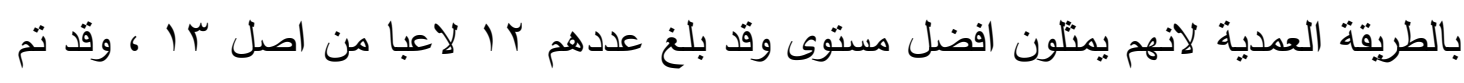
استبعاد لاعب واحد لاصابته. 


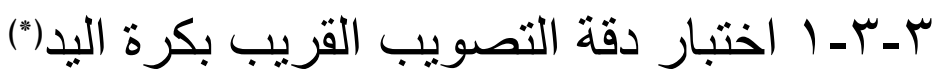

استخدم الباحث هذا الاختبار كاداء لجميع البيانات وكان الغرض من الاختبار هو قياس دقة التصويب القريب من منطقة الوسط وكذلك الزاويتين اليمنى واليسرى ومن الثبات والحركة

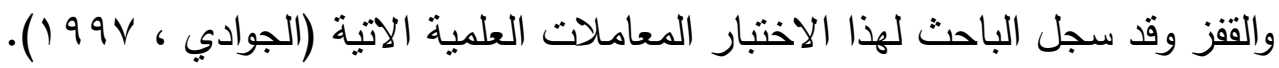
-

فضلا عن ذلك نم ايجاد الصدق الظاهري لهذا الاختبار عن طريق عرضه على النى

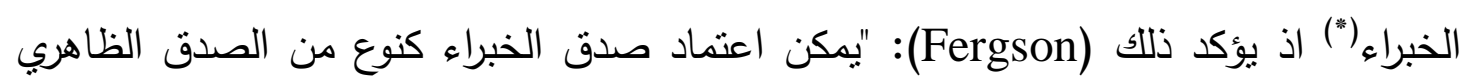
.(Fergson , 1981,104)" - الادوات المستخدمة : (• (1) كرات يد قانونية ، مرمى كرة يد مرسوم على الجدار بداخله

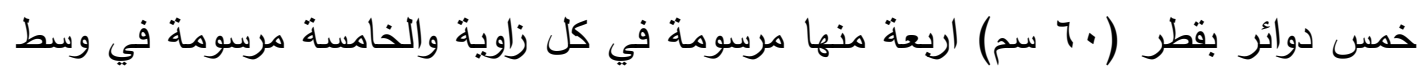
اسفل العارضة.

- طريقة الاداء : يقف اللاعب وبيده الكرة خلف خط منطقة يبعد سبعة عن المرمى ، اذ يقوم

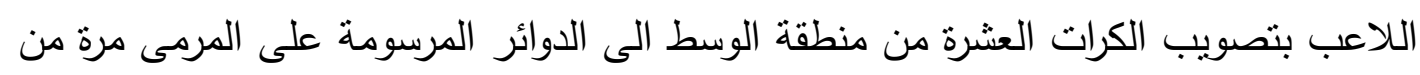

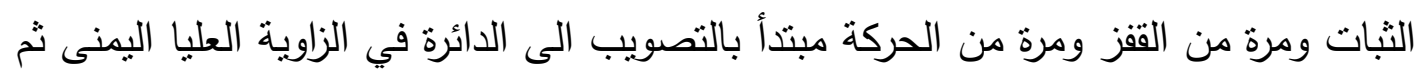

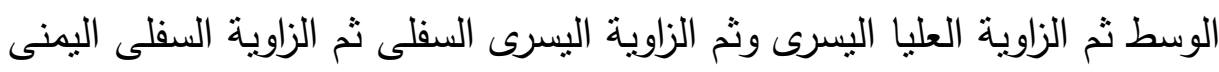
- شروط الاختبار : تعطى لكل مختبر عشر محاولات لكل وضع وبواقع (•r) محاولة لثلاثة

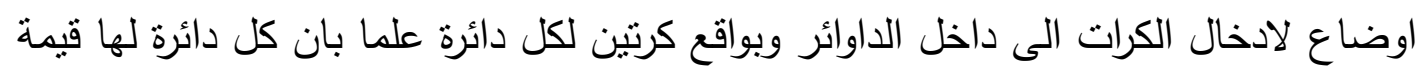

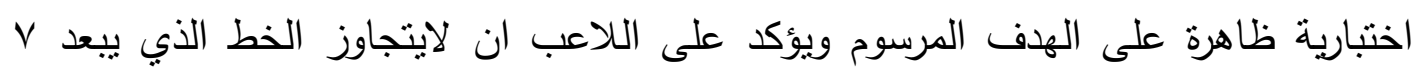

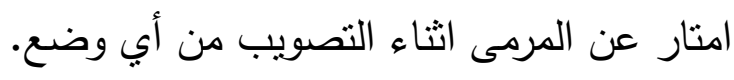

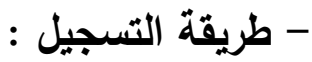
ا ـ يمنح المختبر درجتان لكل كرة تدخل الدوائر في الزاويا العليا اليمنى واليسرى ويمنح درجة

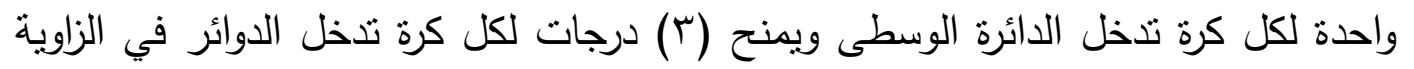

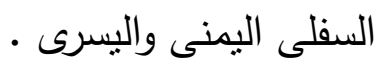
(") يؤدى هذا الاختبار في منطقة الوسط والزاوية اليسرى واليمنى وكذلك من الثبات والحركة والققز

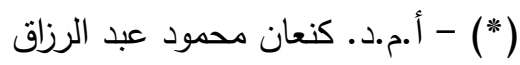

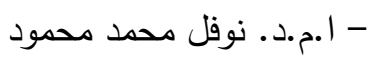
- 
r. المجموع الكلي لدرجات المحاولات العشرة لكل وضع يمثل درجة الدقة الكلية للمختبر والتي

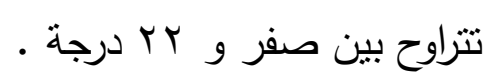

r. يقسم المجموع الكلي على عدد المحاولات العشرة ليمنل الوسط الحسابي لها درجة الدقة

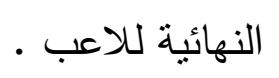

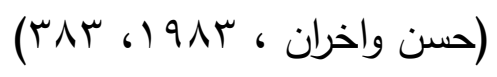

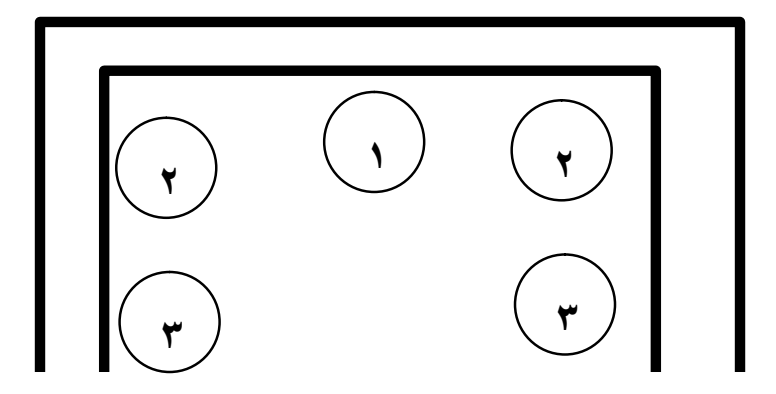

(1) (الشكل (1) (1)

يوضح المرمى المرسوم على الحائط وقيم الدوائر المرسوم بلاخله

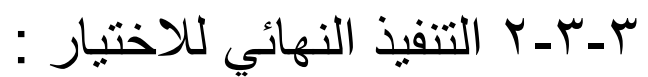
تم اجراء الاختبار من جميع المناطق ومن ثلاثة اوضاع على على عينة البحث في القاعة

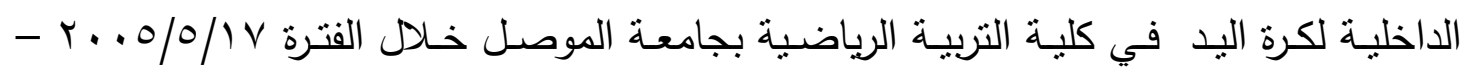
$r .0 / 0 / 19$

وقد اولى الباحث اهتماماً خاصاً لشرح مفردات الاختبار واعطاء فرصة كافية مع اعطاء

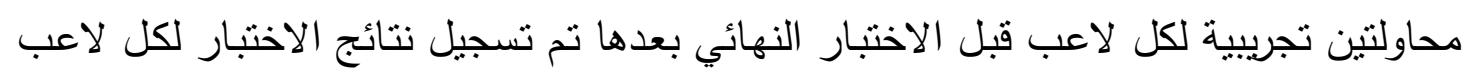

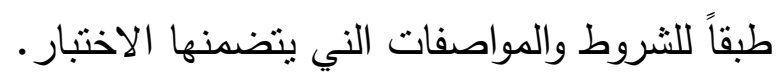

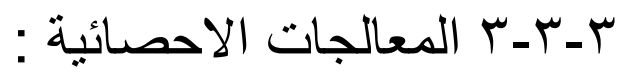

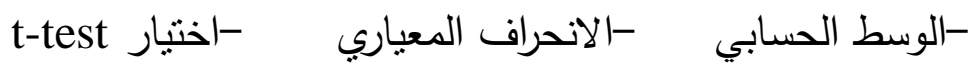

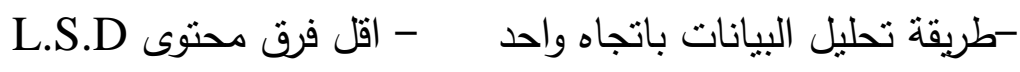

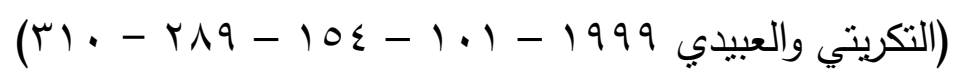

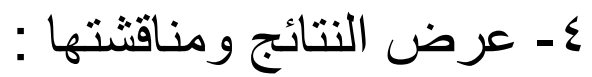

ع - عرض و تحليل نتائج اختيار ات دقة التصويب القريب لعينة البحث :

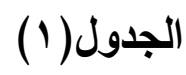


يبين الاوساط الحسابية والانحرافات المعيارية لاختبارات دقة التصويب القريب من منطقة

الوسط والزاوية اليمنى واليسرى ومن اوضاع الثبات والقفز والحركة

\begin{tabular}{|c|c|c|c|c|}
\hline$\varepsilon \pm$ & سَ & 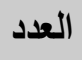 & اسم الاختبار & $ت$ \\
\hline $1, \wedge 0 \cdot \leqslant V$ & IV,ATr & ir & دقة التصويب القريب من الوسط ومن الثبات & 1 \\
\hline l, Ar $\varepsilon \cdot r$ & $17,0 \ldots$ & ir & دقة التصويب القريب من الوسط ومن الققز & r \\
\hline $1, r r \cdot q 1$ & $10,77 V$ & ir & دقة التصويب القربب من الوسط ومن الحركة & $r$ \\
\hline 1,1017 & 17,777 & צו & المجموع الكلي للاختبار ودقة التصويب القريب من الوسط & $\varepsilon$ \\
\hline 1,71 & $1 \leqslant, 01$ & ir & دقة التصويب القريب من منطقة اليسار ومن الثبات(") & 0 \\
\hline $1, \leq 0$ & $1 \pi, 0$ & Ir & دقة التصويب القريب من منطقة اليسار ومن الققز & 7 \\
\hline $1, v 0$ & $M, I V$ & ir & دقة التصويب القريب من منطقة اليسار ومن الحركة & 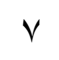 \\
\hline $1, \wedge \vee$ & $\mid r, \leq 1$ & צ & المجموع الكلي للاختبار دقة التصويب القريب من القفز & $\wedge$ \\
\hline $1, r$. & IT,TV & ir & دقة التصويب القريب من منطقة اليمين ومن الثبات & 9 \\
\hline$\cdot, \wedge 0$ & $11,$. & ir & دقة التصويب القريب من منطقة اليمين ومن القفز & 1. \\
\hline$\cdot, V T$ & $9, \wedge r$ & ir & دقة التصويب القريب من منطقة اليمين ومن الحركة & 11 \\
\hline $1,0 \mathrm{r}$ & $11,1 \mathrm{~V}$ & q & \multicolumn{2}{|c|}{ المجموع الكلي لدقة التصويب اليمين } \\
\hline
\end{tabular}

يلاحظ من خلال الجدول ( () أن اعلى وسط حسابي لاختبار دقة التصويب القريب كان

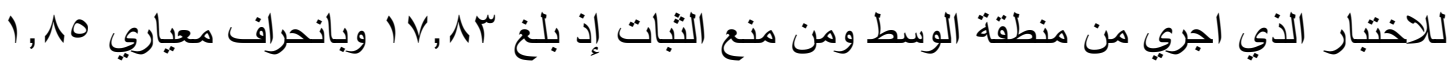

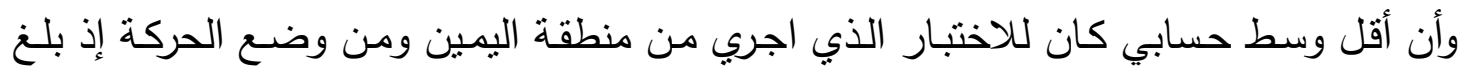

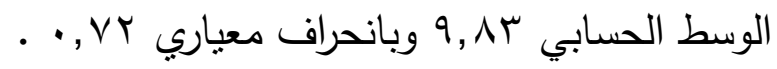

كما يلاحظ من خلال الوسط الحسابي للمجموع الكلي لاختبار دقة التصويب من منطقة

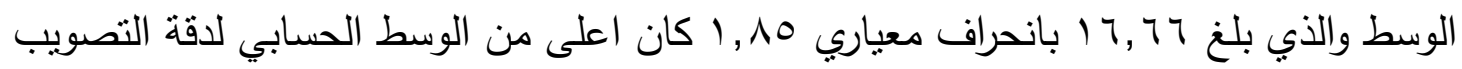

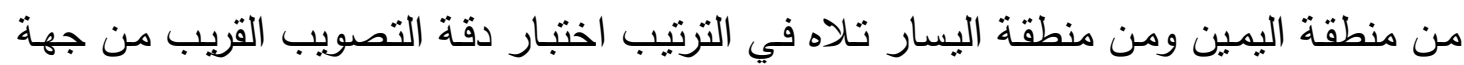

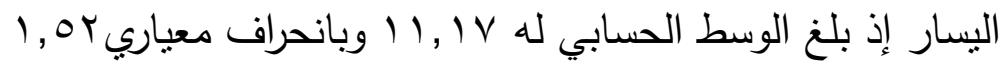

(") منطقة اليسار تعني أن اللاعب يستخدم ذارع اليمين والعكس صحيح للاعبين الذين يستخمون ذراع اليسار. 
ع - ع عرض وتحليل معنوية الفروق للاوساط الحسابية الاختبار ات أن دقة

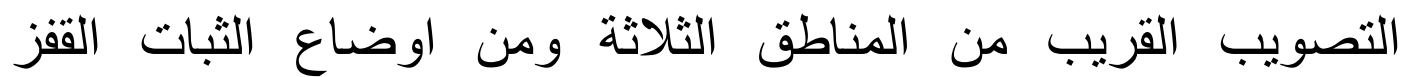
و الحركة :

ولاجل التعرف على معنويـة الفروق في الاوسـاط الحسابية لاختبارات دقة التصويب القريب من منطقة الوسط وكذللك المنطقة اليسرى واليمنى ومن الثبات والقز والحركة تم تحليل

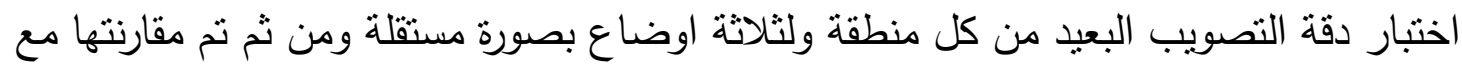
بعضها وصولا لاهداف البحث والتعرف على مدى تحقق فروضه.

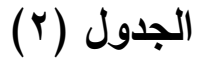

يبين تحليل التباين لنتائج اختبار دقة التصويب القريب من منطقة الوسط ومن اوضاع الثبات

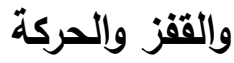

\begin{tabular}{|c|c|c|c|c|c|}
\hline قيمة في & قالمتسة في & المربعات & المربعات & درجات الحرية & \\
\hline \multirow[t]{3}{*}{ r,YTIV } & $* 0,1 \vee 9$ & אחז,乏1 & YA, TTV & $r$ & 1 \\
\hline & & r,V74 & זrז, 91 & rr & $r$ \\
\hline & & & ${ }_{1}, \ldots$ & ro & $r$ \\
\hline
\end{tabular}

يتبين من الجدول(r) وجود فروق ذات دلالة معنوية إذ أن قيمة (ف) المحتسبة والبالغة

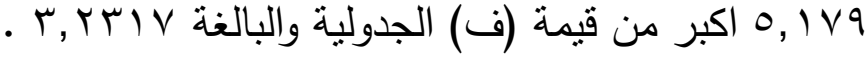

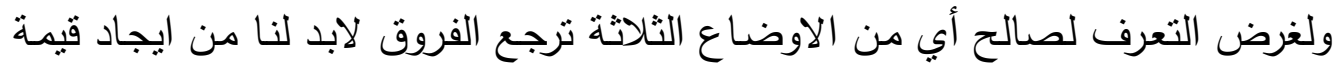
اقل فرق محتوى L.S.D

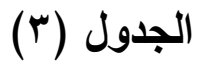

بين معنوية الفروق بين الاوساط الحسابية للاوضاع الثلاثة لدقة التصويب القريب من منطقة الوسط

\begin{tabular}{|c|c|c|c|c|}
\hline الحركة & الققز & الثبات & & وضع التصويب \\
\hline 10,747 & $17,0 \ldots$ & IV,Arrr & سَ & \\
\hline$* Y, 1 T V$ & נזrז 1, & & IV,ATrT & ثبات \\
\hline • & & & $17,0 \ldots$ & قفز \\
\hline & & & 10,777 & حركة \\
\hline
\end{tabular}

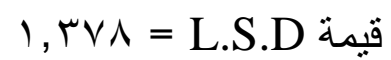




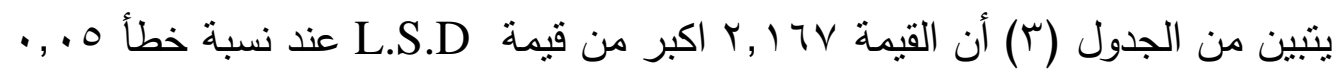

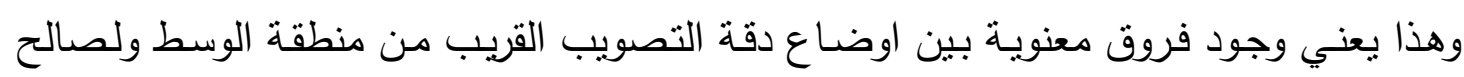

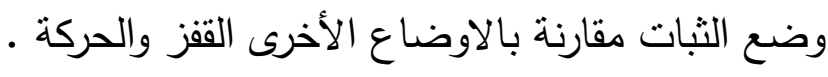

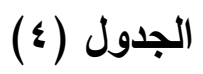

يبين تحليل التباين لنتائج اختبار دقة التصويب القريب من منطقة اليسار ومن اوضاع الثبات، الققز ،والحركة

\begin{tabular}{|c|c|c|c|c|c|}
\hline \multicolumn{2}{|c|}{ قيمة ف } & \multirow{2}{*}{ المربعات } & \multirow{2}{*}{ درجة الحرية } & \multirow{2}{*}{ المربعات } & \multirow{2}{*}{ مصدر التباين } \\
\hline الجدولية & المحتسبة & & & & \\
\hline \multirow{2}{*}{ T,YTIV } & \multirow{2}{*}{ *Y, TYO } & IV,ONT & r & To, ITV & بين المجموعات \\
\hline & & $r, 70 \leqslant$ & Tr & $\Lambda V, O \wedge r$ & داخل المجموعات \\
\hline
\end{tabular}

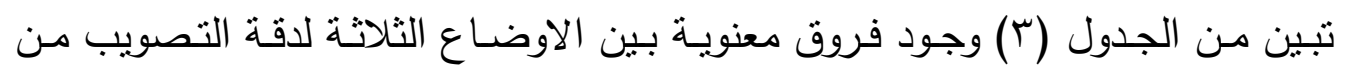

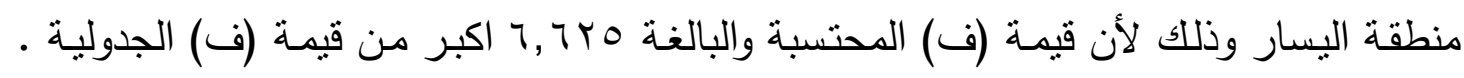
ولاجل التعرف لصالح أي من الاوضاع ترجع الفروق ، لابد لنا من ايجاد قيمة اقل فرق معنوي

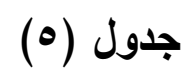

يبين معنوية الفروق بين الاوساط الحسابية للاوضاع الثلاثة لاقة التصويب من منطقة اليسار

\begin{tabular}{|c|c|c|c|c|}
\hline الحركة & القفز & الثبات & & وضع التصويب \\
\hline 14,179 & $1 r, 0$. & $1 \leq, 0 \wedge \mu$ & سَ & \\
\hline$\left.{ }^{*} Y, \Sigma\right) T$ & זrA., & & $1 \leq, \Delta \wedge r$ & الثبات \\
\hline אחז,1 & & & $1 \%, 0$. & القفز \\
\hline & & & 14,174 & الحركة \\
\hline
\end{tabular}

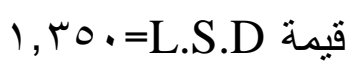

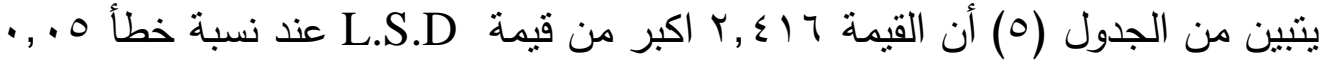

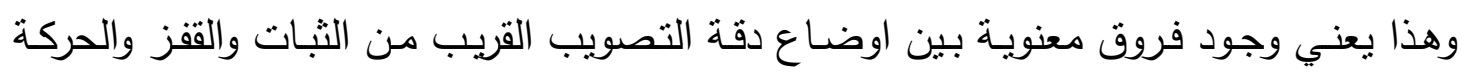

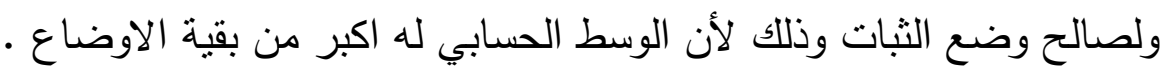


جدول (7)

يبن تحليل التباين لنتائج اختبار دقة التصويب القريب من منطقة اليمين ومن اوضاع الثبات والقفز والحركة

\begin{tabular}{|c|c|c|c|c|c|}
\hline \multicolumn{2}{|c|}{ قيمة ف } & \multirow{2}{*}{ المربعات } & \multirow{2}{*}{ درجة الحرية } & \multirow{2}{*}{ المربعات } & \multirow{2}{*}{ مصدر التباين } \\
\hline الجدولية & المحتسبة & & & & \\
\hline \multirow{3}{*}{$r, r \mu$} & \multirow{3}{*}{$r \varepsilon, \wedge r$} & $r \leqslant, r T r$ & $r$ & $\varepsilon \Lambda, T \neg \vee$ & بين المجموعات \\
\hline & & $\cdot, 9 \wedge$ & זr & שTr, & داخل المجموعات \\
\hline & & & ro & $11, \ldots$ & المجموع الكلي \\
\hline
\end{tabular}

يتبين من الجدول (†) وجود فروق معنوية بين الاوضاع الثلاثة لدقة التصويب القريب

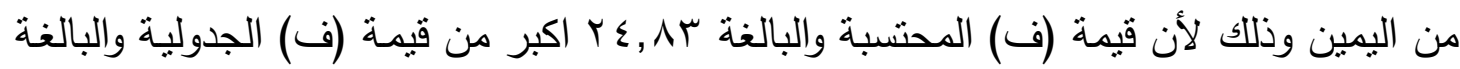

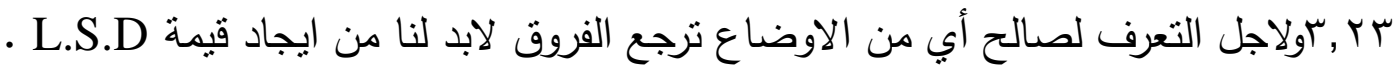
جدول (v)

يبين معنوية الفروق بين الاوساط الحسابية للاوضاع الثلاثة لدقة التصويب القريب من اليمين

\begin{tabular}{|c|c|c|c|c|}
\hline الحركة & القفز & الثبات & & وضع التصويب \\
\hline q,Arr & $11, \ldots$ & צ' & سَ & \\
\hline "r, " & $" 1,777$ & & צד. & الثبات \\
\hline $1,17 \mathrm{~V}$ & & & $11, \ldots$ & الققز \\
\hline & & & Q,人rr & الحركة \\
\hline
\end{tabular}

$$
\text { قيمة }
$$

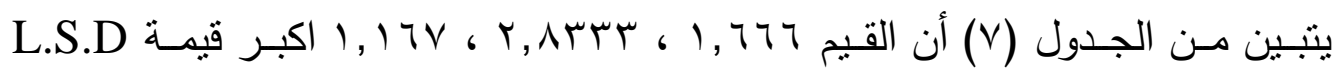

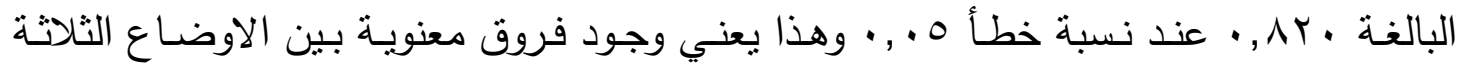
ولصالح وضع النبات مقارنة بوضع القفز والحركة ثم لصالح وضع القفز مقارنة بوضع الحركة

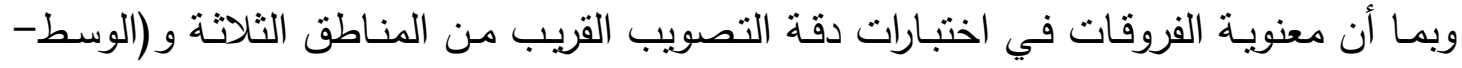

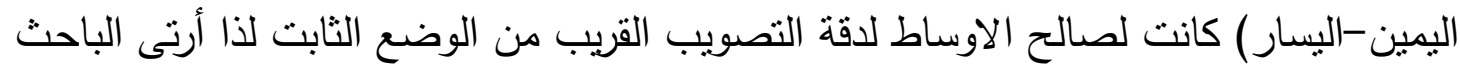

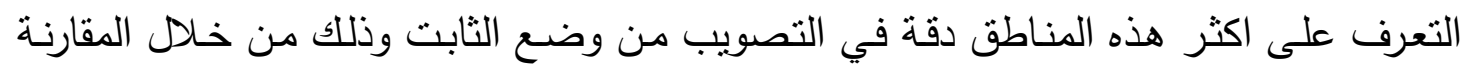
باجراء عملية تحليل التباين بين الاوساط الحسابية لدقة التصويب القريب من وضع الثبات ومن منطقة الوسط واليمين واليسار

جدول (^) 
يبين تحليل التباين للاوساط الحسابية لاختبارات دقة التصويب القريب من الثبات ومن

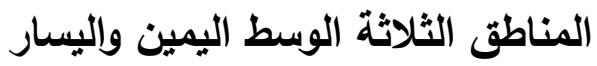

\begin{tabular}{|c|c|c|c|c|c|}
\hline \multicolumn{2}{|c|}{ قيمة ف } & \multirow{2}{*}{ المربعات } & \multirow{2}{*}{ درجة الحرية } & \multirow{2}{*}{ المريعات } & \multirow{2}{*}{ مصدر التباين } \\
\hline الجدولية & المحتسبة & & & & \\
\hline \multirow{3}{*}{ T,YMIV } & \multirow{3}{*}{$r \cdot, 97 r$} & $(1,, \wedge 71$ & r & ITT,VYY & بين المجموعات \\
\hline & & $Y, T \leq \varepsilon$ & זr & NV, YO. & داخل المجموعات \\
\hline & & & ro & Yo., 9Vr & المجموع الكلي \\
\hline
\end{tabular}

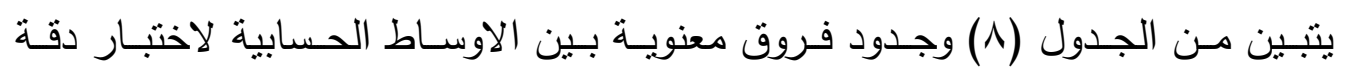
التصويب القريب من الثبات ومن المناطق الوسط اليمين واليسار وذلك لأن قيمة (ف) المحتسبة

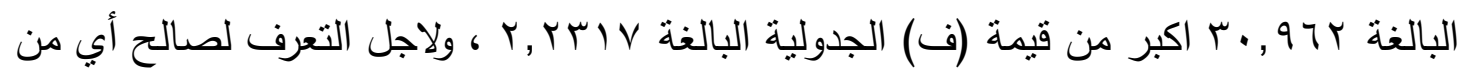

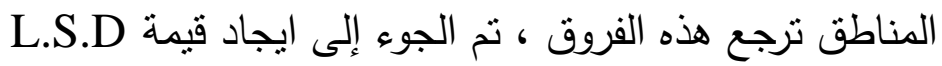

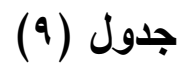

يبين معنوية الفروق بين الاوساط الحسابية لاختبارات دقة التصويب القريب من الثبات ومناطق الوسط واليمين واليسار

\begin{tabular}{|c|c|c|c|c|}
\hline اليمين & اليسار & الوسط & & جهة التصويب \\
\hline וצ.74 & I \&,OAr & IV,Arr & سَ سَ & \\
\hline 0,177 & "r, ro. & & IV,Ar & الوسط \\
\hline \multirow[t]{2}{*}{1,917} & & & $1 \leq, 0 \wedge r$ & اليسار \\
\hline & & & 14,777 & اليمين \\
\hline
\end{tabular}

تبين من الجدول (9) وجود فروق ذات دلالة معنوية بين الاوساط الحسابية لاختبارات

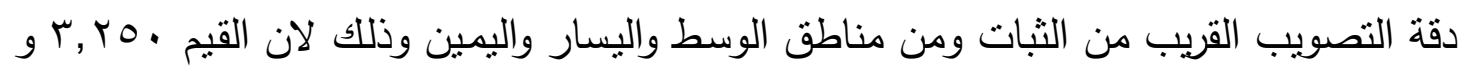

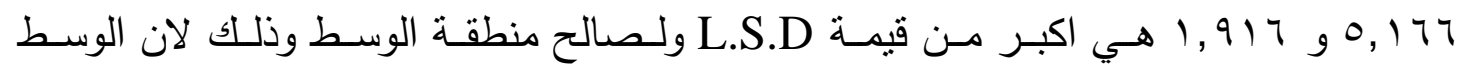
الحسابي لاختبار دقة التصويب القريب من الوسط اكبر من الاوساط الحسابية لمنطقة اليسار 
من خـلال الجدول ا يتبين بـأن دقـة التصويب القريب من منطقة الوسط ومن كافه الوضعيات الثبات - الحركة - الققز كانت اكبر من الاقة للهناطق الأخرى اليسار واليمين وتتقق

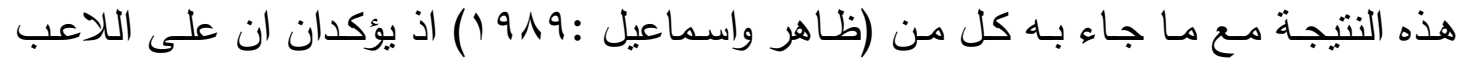

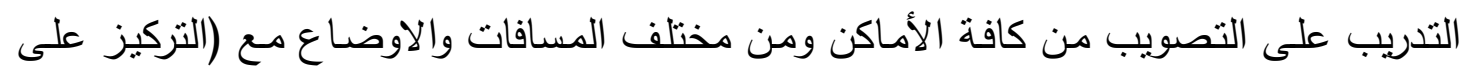

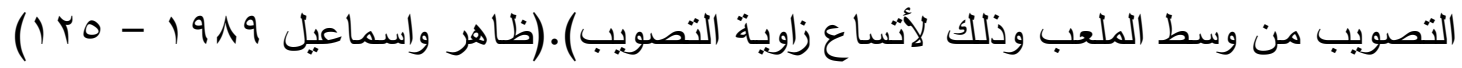
ومن خلال الجداول V.06، T، تبين بان دقة التصويب القريب من وضع الثبات كانت اكبر من الاوضـاع الأخرى (القفز والحركة) ولجميع المناطق التي تؤدي منها التصويب ويعزو الباحث

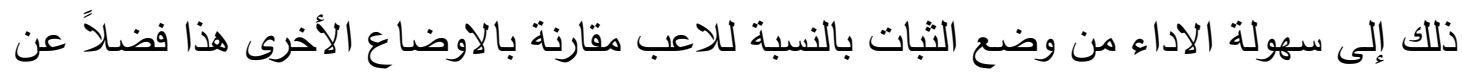

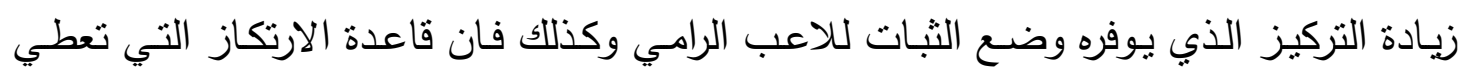

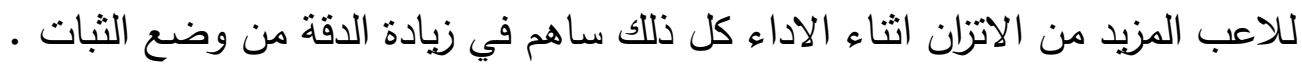

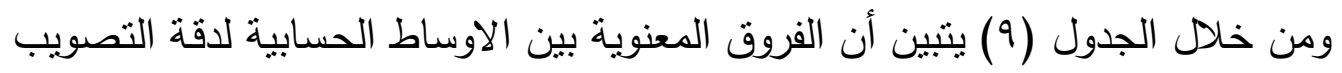

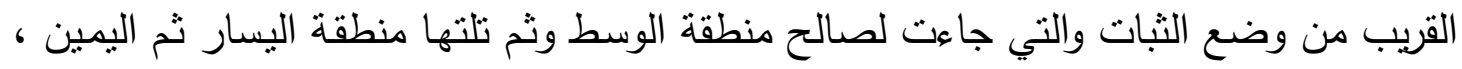

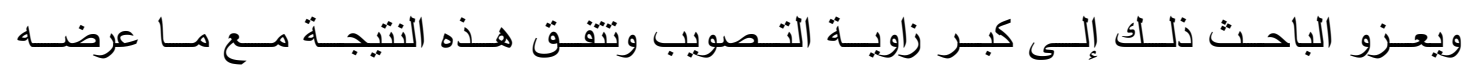

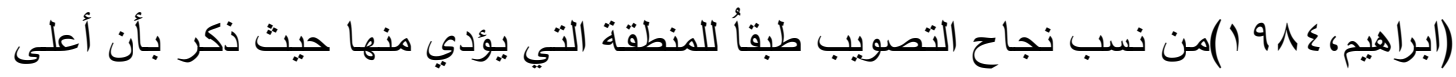
نسبة كانت للتصويب من الوسط تلتها منطقة الساعد ثم منطقة اليسار .(إبراهيم عد19 1 - . ^)

\section{0 - الاستتناجات والتوصيات :

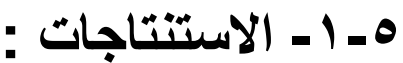

ا ـ أن للوضع الذب يؤدي منه التصويب القريب نأثيراً كبيراً في دقته ومن أبي منطقة يؤدي منها

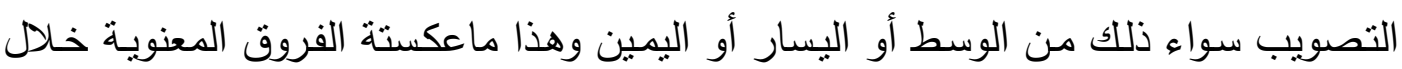
مقارنة المتوسطات الحسابية والتي كانت لصالح وضع الثبات ولجميع المناطق الوسط واليمين الونين

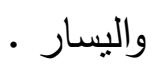

r. أن للمنطقة التي يؤدي منها التصويب القريب تأثيراً كبيراً في دقته وهذا ما عكسته الفروق المعنوية من خلال المتوسطات الحسابية لدقة التصويب من منطقة الوسط واليسار واليمين والتي جاءت لصالح منطقة الوسط مقارنة بمنطقة اليسار ومنطقة اليمين

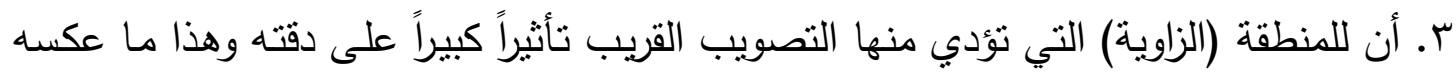

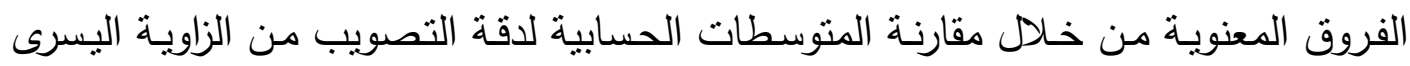

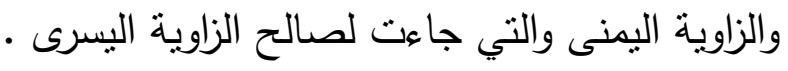


في ضوء النتائج وفي حدود عينة البحث يوصي الباحث ا ـ الاهتمام في إثناء التدريب على التصويب القريب من المنطقة المواجهة للمرمى ومن كافة لئة

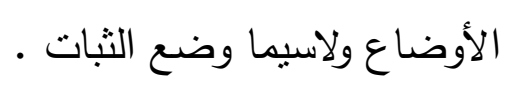

r. الاهتمام في إثثاء التدريب على التصويب القريب من الزاويـة ولاسيما الزاوية عكس مههـة

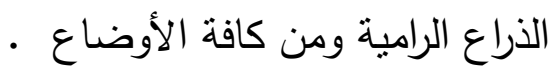
r. عدم المجازفة والتصويب من جهة الذراع الرامية(الزاوية اليمنى) الا في الحالات الحرجة.

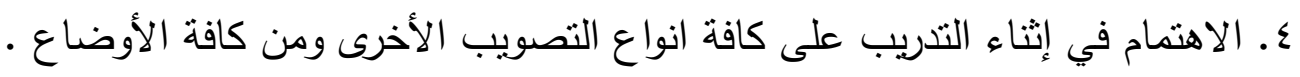

\section{المصادر}

1. إبراهيم، منير جرجيس : ـ1911 ، كرة اليد للجميع ، مطبعة دار الثعب ، القاهرة .

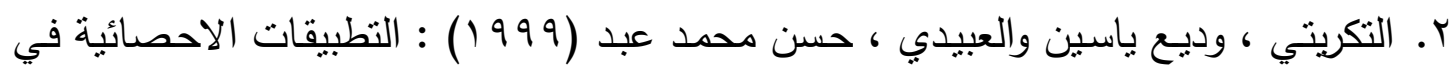

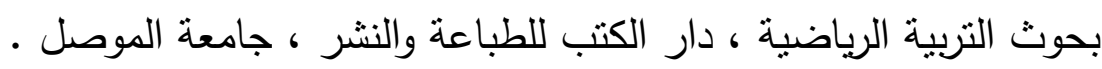

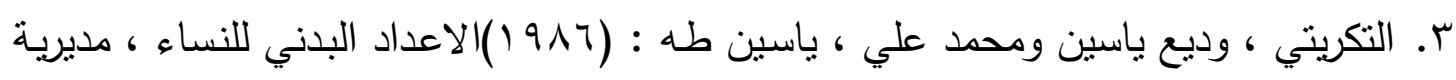
دار الكتب للطباعة والنشر ، جامعة الموصل .

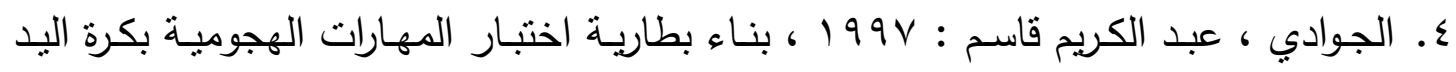
لطلاب التربيـة الرياضية جامعة الموصل ، اطروحـة دكتوراه غبر منشورة ، كليـة التربيـة

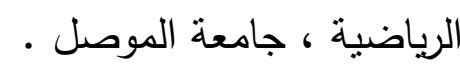
ه. حسن ، سليمان علي ، واخران : بر191 ، المبادئ التدريبية والخططية في كرة اليد ، مديرية

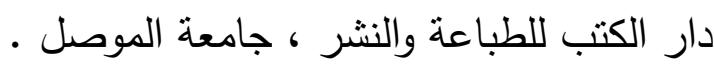

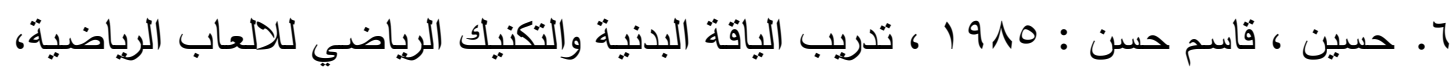

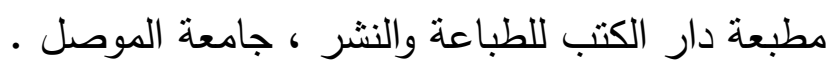

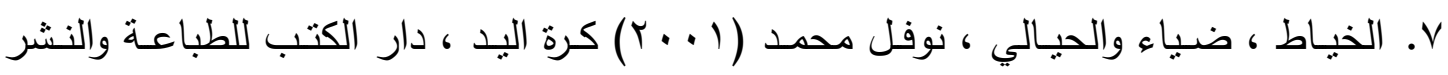

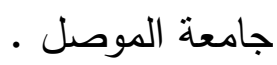

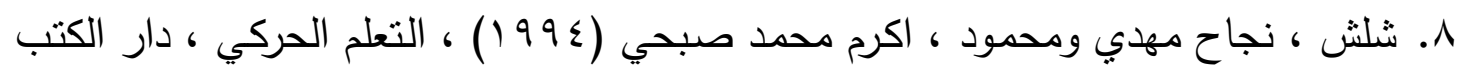

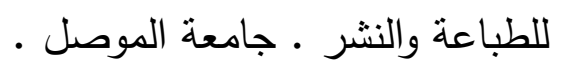
9 9. الثيخو ، خالد فيصل :1919 1 : تقويم حالات التهديف القريب والبعيد لبطولة صدام الدولية بكرة اليد ، رسالة ماجستير غير منشورة ، كلية التربية الرياضية ، جامعة الموصل .

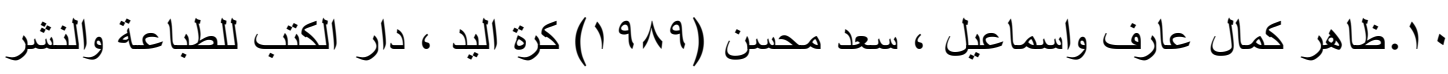

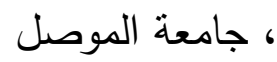

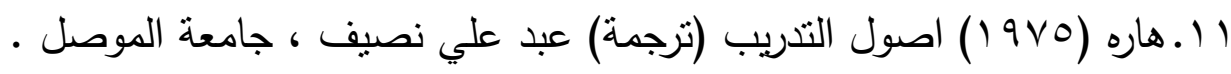


12.Erwin singer 1972: Hallen Handball , Tecknik , Taktik Konditionsardett, Queck verlag stutt gart .

13.Fergson,Geoge , 1981: statistical analysis in psychology and Education, McGraw Hill, New York.

14.Neil, Graham 1976 : modern Team handball Beginner to Expert Monteral Mcgill, University printing service .

15.Shaver , Larry, G 1981: Essenlional of exercise phsiology Bargess publishing Company. 